\title{
Silicon carbide LED
}

\author{
S.I. Vlaskina \\ Institute of Semiconductor Physics, NAS of Ukraine, 45 prospect Nauky, 03028 Kyiv, Ukraine \\ Phone: +380 (44) 269 3792; fax +380 (44) 265 8342; e-mail: businkaa@mail.ru \\ Dong Seoul College, 461-714, 423, Bokjung-Dong, Sungnam-city, Kyonggi-do, Korea \\ Phone: 82 (031) 720 2141; fax: 82 (031) 720 2261; e-mail: svitlana@haksan.dsc.ac.kr
}

\begin{abstract}
Silicon carbide has been widely used as material for manufacturing yellow, red, green LED and optoelecronics devices (indicators, screens). The silicon carbide LED technology has been investigated for improvement of their operational characteristics. This includes the influences of the surface processing (etching, annealing), the formation method for the $p-n$ junctions and the contacts on the LED properties. Light-emitting devices used as light sources for optical-fiber communication lines. LED fabricated by $\mathrm{Al}^{+}$ion-implanted in $6 \mathrm{H}-\mathrm{SiC}$ and investigated their characteristics for an effective green LED. The brightness of the ion-implanted $p-n$ junction was found to be two orders higher than that of diffusion $p-n$ junction, and the best value was $2000-10000 \mathrm{~cd} / \mathrm{m}^{2}$ with passing current about $0.5 \mathrm{~mA}$ through area $50 \times 50 \mu \mathrm{m}$ and applied voltage about $2.6 \pm 0.2 \mathrm{~V}$. The ion-implanted structures showed a high stability of light in the temperature range of $77-600 \mathrm{~K}$.
\end{abstract}

Keywords: silicon carbide, LED, ion implantation.

Paper received 05.02.02; revised manuscript received 08.02.02; accepted for publication 05.03.02.

\section{Introduction}

Silicon carbide LED first became a significant commercial success when CREE (USA) got them on the market in the early 1990's. Today CREE's CB series of super bright LED are a new generation of solid-state LED emitters, which combine highly efficient InGaN with Cree's $\mathrm{SiC}$ substrate. Cree's main LED products now have $\mathrm{SiC}$ as a substrate for gallium nitride or indium gallium nitride as active ingredients, and emit blue as well as green and blue-green luminescence. Yellow silicon carbide LED's had been made around 1970 - 1975 in the former Soviet Union. Diffusion $p$ - $n$ junctions had been applied to manufacturing this LED devices. Single crystalline $\mathrm{SiC}$ with $\mathrm{N}_{\mathrm{D}}-\mathrm{N}_{\mathrm{A}}=(1 \sim 5) \cdot 10^{18} \mathrm{~cm}^{-3}$ was suitable for manufacturing such devices. The diffusion factors depend on the concentrations of the impurities in the crystals. The process of $p-n$ junction creation is rather complicated because the usual impurity concentrations in crystals range from $10^{17}$ to $10^{18} \mathrm{~cm}^{-3}$. The optimal depth $(1 \mu \mathrm{m})$ of the $p-n$ junction had been obtained with industrial crystals [1].

To obtain a high manufacturing yield for LED with uniform light, the following technique had been applied. Diffusion of $\mathrm{Al}$ with $\mathrm{O}$ was carried out for $2 \mathrm{hr}$ at $1700^{\circ} \mathrm{C}$. Then, $\mathrm{B}$ and $\mathrm{Al}$ were introduced for $15 \mathrm{~min}$ at $1600^{\circ} \mathrm{C}$. The sources for $\mathrm{O}, \mathrm{Al}$, and $\mathrm{B}$ were $\mathrm{SiO}, 99.99 \% \mathrm{Al}$ and $\mathrm{B}_{2} \mathrm{O}_{3}$, respectively. After the diffusion processes, appreciable changes in the surface morphology or the carbon traces were observed using optical microscopy. The low-temperature $(77 \mathrm{~K})$ and the high-temperature (300 $\mathrm{K})$ photoluminescence in the ultraviolet wavelength range showed repeatable and clear spectra for the uniformly doped samples. Diffusion of $\mathrm{Al}$ and $\mathrm{O}$ above $1700^{\circ} \mathrm{C}$ resulted in a deterioration of the surface conditions, and diffusion of $\mathrm{B}$ and $\mathrm{Al}$ at higher temperatures made the photoluminescence spectra less clear and the surface conditions even worse. The time at optimum temperature could be adjusted to change the color of electro-luminescence from yellow-green to red (in the wavelength range between 5600 and $6000 \AA$ ). In the case of a yellow-green color (5600 $)$ ), the time for the diffusion of $\mathrm{B}$ and $\mathrm{Al}$ turned out to be 20 $25 \mathrm{~min}$. A further increase in the diffusion time caused the $p-n$ junction to be less sharp as well as the voltage drop on the $p$-layer to increase, and, consequently, spreading of 


\section{S. I. Vlaskina: Silicon carbide LED}

the current carriers on the $p$-layer and less clear light drawings on the displays. At the shortest diffusion time ( $5 \mathrm{~min})$ for $\mathrm{B}$ and $\mathrm{Al}$, the thickness of the $p$ - $n$ junction was too small to assure an effective LED. The parameters of such LED and indicators, which had been fabricated, are listed in Table 1. Usage of another SiC polytypes (4H, 3C, 15R) allows to change the color of light, too.

Because of the extreme stability of silicon carbide, it is not necessary to dope the crystal by thermal diffusion. Instead, dopants can be introduced by ion implantation. Once implanted into the crystal, the dopant atoms occupy interstitial positions in the lattice and must be transferred to substitution sites to become electrically active. This "activation" is accomplished by high temperature annealing in an inert ambient such as argon.

Nitrogen and phosphorous are typical $n$-type dopants in $\mathrm{SiC}$.
LED, but higher stability, more simple design (without $\mathrm{AlGaN}$ or GaN layers) and can be used in various usual applications.

\section{Experiment}

Green LED had been prepared by the method of ionimplantation of impurities into $6 \mathrm{H}-\mathrm{SiC}$ crystals. $\mathrm{Al}^{+}$-implanted for $p-n$ junctions in $6 \mathrm{H}-\mathrm{SiC}$ substrates and their characteristics were investigated as an effective LED. The ion-implantation was carried out on polished $n$-type $6 \mathrm{H}$ $\mathrm{SiC}$ crystals and on epitaxial layers of $6 \mathrm{H}-\mathrm{SiC}$ with an impurity concentration of $\mathrm{N}_{\mathrm{D}}-\mathrm{N}_{\mathrm{A}}=(2-8) \cdot 10^{18} \mathrm{~cm}^{-3}$. Substrate was doped by donor nitrogen. Implantation was performed with $80 \mathrm{keV} \mathrm{Al}^{+}$by using an ion accelerator. The implanted depth was $0.5 \mu \mathrm{m}$, and the concentration of $\mathrm{Al}$ was $10^{20} \mathrm{~cm}^{-3}$.

Table 1. LED (diffusion p-n junction) on $6 \mathrm{H}-\mathrm{SiC}$.

\begin{tabular}{|c|c|c|c|c|c|}
\hline "Device & $\begin{array}{l}\text { Light } \\
\text { voltage } \\
\text { (V) }\end{array}$ & $\begin{array}{l}\text { Light } \\
\text { current } \\
(\mathrm{mA})\end{array}$ & $\begin{array}{l}\text { Working } \\
\text { voltage } \\
\text { (V) }\end{array}$ & $\begin{array}{l}\text { Brightness } \\
\left(\mathrm{cd} / \mathrm{m}^{2}\right)\end{array}$ & $\begin{array}{c}\text { Size of } \\
\text { light area } \\
\left(\mu \mathrm{m}^{2}\right)\end{array}$ \\
\hline $\begin{array}{l}\text { LED indicator } \\
\text { (10 elements) }\end{array}$ & 2.2 & 5 & $2.4 \pm 0.2$ & $30-80$ & $800 \times 300$ \\
\hline $\begin{array}{l}\text { LED matrix } \\
\text { (64 elements) }\end{array}$ & $2.5 \pm 0.1$ & 0.5 & $3.0 \pm 0.2$ & 60 & $\begin{array}{r}120 \times 120 \\
\text { step } 100\end{array}$ \\
\hline $\begin{array}{l}\text { LED break with } \\
\text { high resolution } \\
\text { (64 elements) }\end{array}$ & $2.4 \pm 0.2$ & 2.5 & $3.1 \pm 0.1$ & 70 & $\begin{array}{r}40 \times 40 \\
\text { step } 60\end{array}$ \\
\hline $\begin{array}{l}\text { LED break } \\
\text { (100 elements) }\end{array}$ & $2.4 \pm 0.2$ & 0.5 & $2.8 \pm 0.1$ & 80 & $\begin{array}{r}100 \times 100 \\
\text { step } 100 \\
\end{array}$ \\
\hline $\begin{array}{l}\text { LED break with } \\
\text { face conclusion } \\
\text { of light (step 100) }\end{array}$ & & & & & $\begin{array}{l}40 \times 40 \\
\text { step } 60\end{array}$ \\
\hline
\end{tabular}

Aluminum and boron are $p$-type dopants. Implantation is usually conducted with the sample at elevated temperatures $\left(600-800{ }^{\circ} \mathrm{C}\right)$ to provide some in-situ annealing of lattice damages caused by the implant. The implanted sample is subsequently annealed at temperatures $1000-1700{ }^{\circ} \mathrm{C}$ for times 5 and 90 minutes to activate the dopants. The dynamics of activation depends both on the dopant species (i.e. aluminum and boron, nitrogen and phosphorus) and upon the $\mathrm{SiC}$ polytype (i.e., $4 \mathrm{H}$ or $6 \mathrm{H}$ ). Activation of nitrogen implants in $4 \mathrm{H}-\mathrm{SiC}$ requires higher annealing temperatures than those in $6 \mathrm{H}-\mathrm{SiC}$.

Phosphorus is an excellent $n$-type dopant in $4 \mathrm{H}-\mathrm{SiC}$ when implanted at high doses, such as for source and drain regions of MOSFET. $p$-type dopants, aluminum and boron, require much higher temperatures for efficient activation and temperatures above of $1650{ }^{\circ} \mathrm{C}$ are nescessary for that. Aluminum implants typically achieve the same degree of activation at annealing temperatures about $100{ }^{\circ} \mathrm{C}$ lower than boron. At any given annealing temperature, there exists an optimum annealing time [2]. This article reports results of SiC green LED electrical characterization. This LED had the same brightness as CREE's
The optimum implantation time and the substrate temperature were $2 \mathrm{~min}$ and $660^{\circ} \mathrm{C}$, respectively.

Despite the low resistance of the $p$-layers, a thin highresistive layer of $\mathrm{C}$ was formed on the surface of the crystals after implantation. This $\mathrm{C}$ film reduced the adhesion of the metals deposited for the contacts, increased the resistance of the contacts to the $p$-layers, and worsened the light uniformity. The crystals were annealed at 800 $1100^{\circ} \mathrm{C}$ for $2-10 \mathrm{~min}$ to remove the $\mathrm{C}$ layer and to reduce the quantities of radioactive defects. Before the LED fabrication process, the crystals were etched in an acid mixture of $\mathrm{HF}$ and $\mathrm{HNO}_{3}$.

Contacts were prepared by deposition of Al layer on $p$-SiC heated to the temperature $550{ }^{\circ} \mathrm{C}$ in vacuum (implanted and annealed). Al contact thickness was less or about $4000 \AA$. Ni layers was deposited for protection of Al layer from oxidation and for better contact with wire during LED manufacturing. Thickness of Ni layer was about $2000 \AA$. Contacts to the $n$-SiC substrate were made by laser using $\mathrm{Ti}$ and $\mathrm{Ni}$ wire. Contact of necessary configuration were made by photolithography methods. Photos of prepared LED are shown in Fig.1 (a, b, c). 


\section{S. I. Vlaskina: Silicon carbide LED}

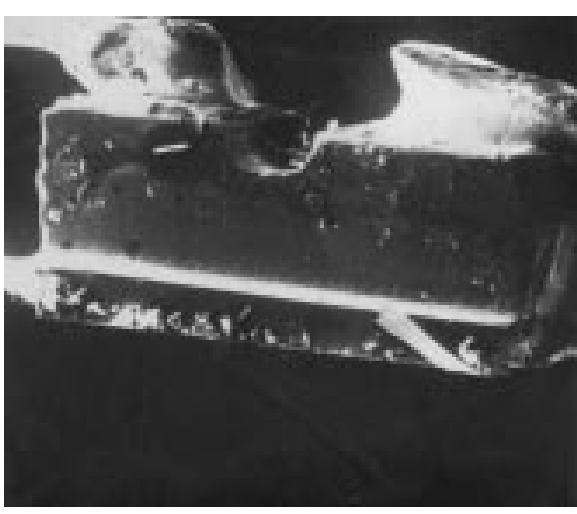

$a$

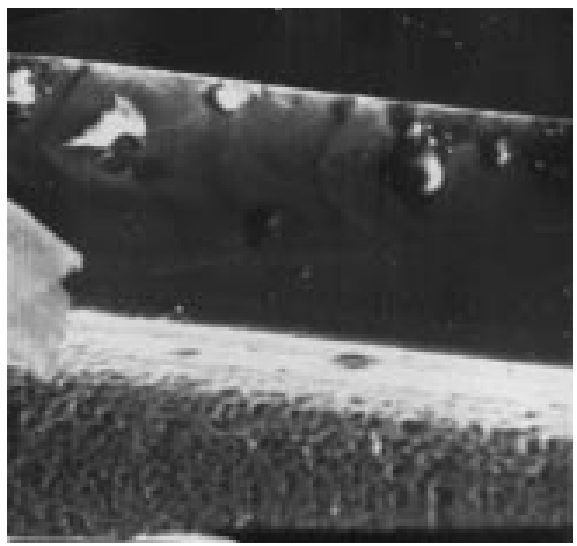

$b$

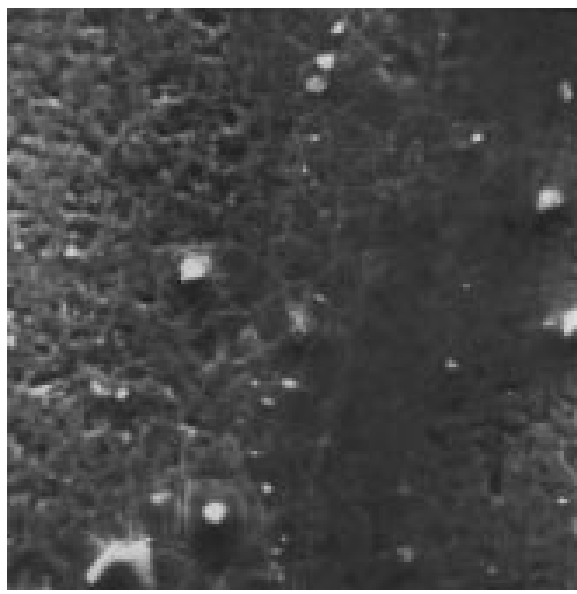

$c$

Fig. 1. Micro photo of ion-implanted LED: magnitude: $a-{ }^{x} 75 ; b-{ }^{x} 380 ; c-{ }^{x} 730$.

Just this LED was made on $n$-epitaxial layer grown by Tairov's method. The boundary between $n$-layer and implanted $p$-layer is shown. The block structure of epilayer and $p-n$ junction is also shown. Single crystals grown by the Lely method had been used for such

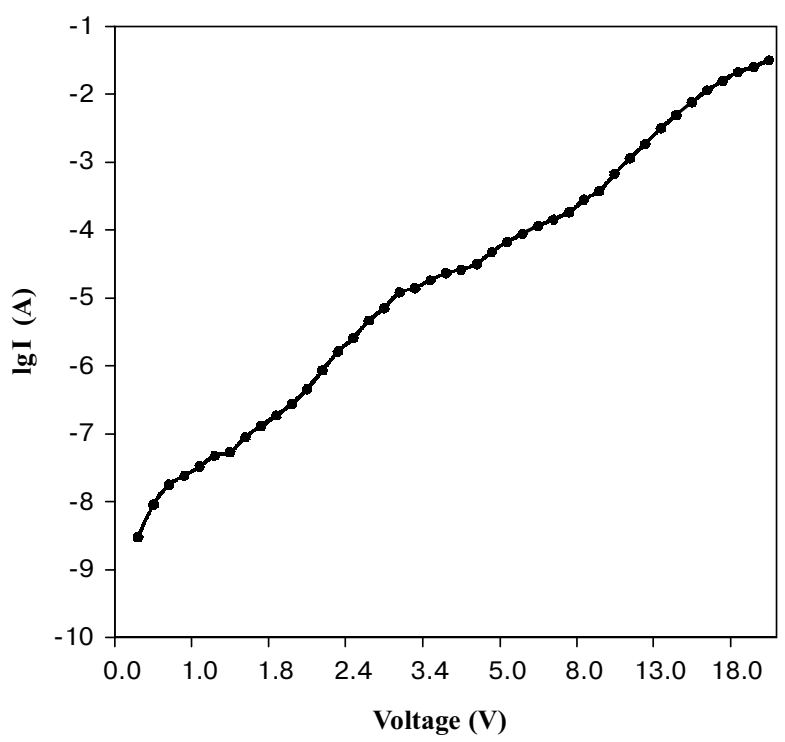

Fig. 2. Voltage-current characteristic of ion implanted p-n junction in $6 \mathrm{H}-\mathrm{SiC}$.

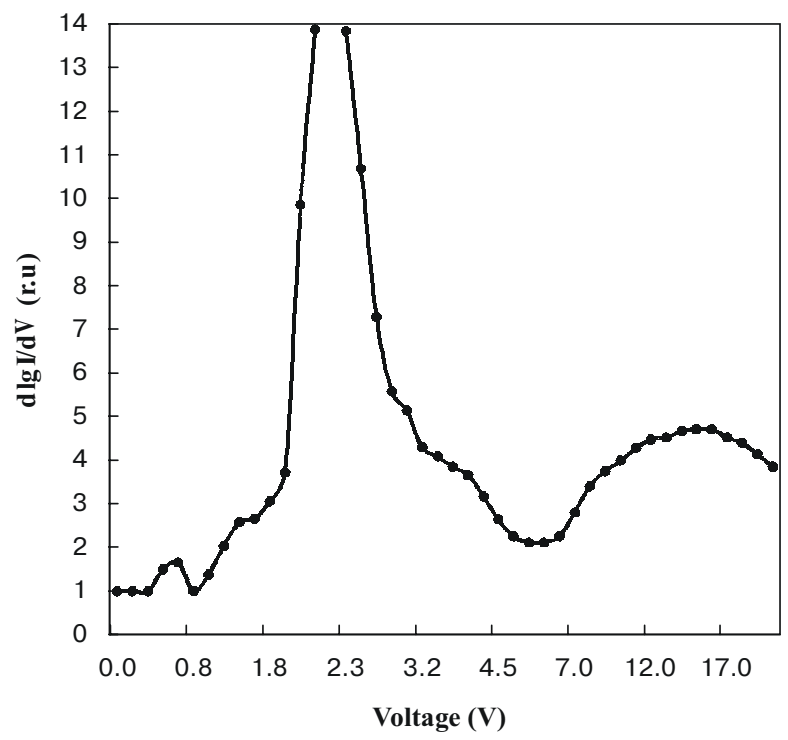

Fig. 3. Derivation from voltage-current characteristic of ion implanted LED.

LEDs, too, but photos of epilayers with implanted aluminum are more interesting than these of single crystals with $p-n$ junction.

The voltage-current characteristics of ion-implanted $p-n$ junctions are shown in Fig. 2.

The differential degree:

$\alpha=\mathrm{dlgI} / \mathrm{dV}$ is shown in Fig. 3 .

In the low voltage area (at a voltages less then $0.08 \mathrm{~V}) \alpha$ is about unity. Determined from this linear site leakage is $(1-2) \cdot 10^{4} \Omega$. The reason of such resistance is carbon or silicon oxide on the surface of LED.

In the region of very small voltages:

$$
I=I_{0} \exp \left(V / V_{\mathrm{T}}\right) \text {. }
$$

This circumstance, as well as independence of $V_{\mathrm{T}}$ on temperature permits to think about tunnel character of 


\section{S. I. Vlaskina: Silicon carbide LED}

this part of the voltage-current characteristics. Concentration evaluated from a volume charge is as follows:

$$
N=\frac{1}{e}\left|\int_{n_{s}}^{n_{n}} \frac{\rho(n)}{n} d n\right|=\frac{\pi^{2} \varepsilon m}{32 h^{2}} V_{T}^{2}
$$

$N$ about (1-4) $\cdot 10^{20} \mathrm{~cm}^{-3}$ is indicative of a rather high doping level of the junction. The ideality factor 1.9 to 3.2 was obtained from the following exponential part of the forward bias current-voltage characteristics. The forward saturation current was (3-5) $10^{-16}$ to $(3-5) \cdot 10^{-8} \mathrm{~A} / \mathrm{cm}^{2}$ and forward turn-on voltage of 0.8 to $2 \mathrm{~V}$ (at current density about (5-8) $10^{-8} \mathrm{~A} / \mathrm{cm}^{2}$. Reverse biasing produced average leakage currents were that were of the order of $10^{-8}$ to $10^{-3} \mathrm{~A} / \mathrm{cm}^{2}$ (at 10 to $20 \mathrm{~V}$ reverse bias).

The ideality factor had some trends. Namely, the ideality factor is decreased and forward current density is increased with increasing operation temperature in the range of $20^{\circ} \mathrm{C}$ to $400{ }^{\circ} \mathrm{C}$. The ideality factor is of the order of 2 for most LED suggesting that recombination/ generation current is dominant over diffusion current. The ion-implanted $p$ - $n$ junctions are sharp, and the injection of carriers as well as their recombination in the $p$ layer prevail. The sharpness was maintained in the temperature range between 77 and $500 \mathrm{~K}$. Recombination happens in the layer of the volume charge in the $p$ - $n$ junction at low levels of injection, but the recombination prevails in either the $p$ - or the $n$-area at high levels of injection, depending on the doping degree.

In the region of voltages changing from $2.2 \mathrm{~V}$ to $18 \mathrm{~V}$ the $\alpha$ degree is reduced passing the flat minimum. Then $\alpha$ degree (Figs 2, 3) is again increased and can be described by the expression:

$$
V=\left\{\begin{array}{c}
A I^{\frac{1}{2}}+V_{0} \\
B I^{\frac{1}{4}}+V_{\infty}
\end{array}\right\}
$$

The square-law part of the voltage-current characteristics enables to calculate the major carrier lifetime near the cathode:

$$
\tau_{n_{k}}=\frac{L^{2}}{2 \mu V_{0}}=(0.8-1.2) \cdot 10^{-8} s
$$

$\left(\mu_{\mathrm{n}}=100 \mathrm{~cm}^{2} / \mathrm{Vs}\right)$.

That is in good agreement with the experimental data of transitive characteristics, where ignition time is (2.5$3) \cdot 10^{-8} \mathrm{~s}$ and emission time is $(1-1.5) \cdot 10^{-8} \mathrm{~s}$.

The light-brightness characteristic of the ion-implanted $p-n$ junction is shown in Fig. 4. The differential degree $\beta=\mathrm{dB} / \mathrm{d} \lg \mathrm{I}$ is shown in Fig. 5. The linear region extends from $7 \cdot 10^{-4} \mathrm{~A}$ to $10^{-2} \mathrm{~A} / \mathrm{cm}^{2}$. The high stability of the light, even at 77-600 K, is another characteristic for the ion-implanted structures, which is understood mainly by the role of the radioactive defects in the emission. The concentration of defects is constant in the temperature range of 77$600 \mathrm{~K}$.

The destructive features of the ion-implanted structures produced narrow lines in the electro-luminescence spectra at relatively small current (Fig. 6) A correlation between

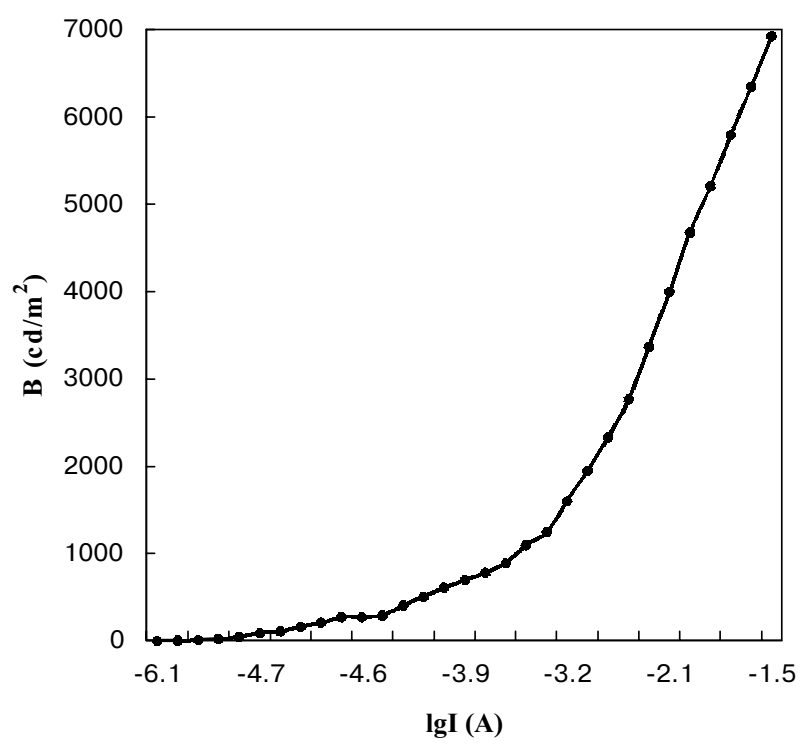

Fig. 4. Ion-implanted $p-n$ junction light brightness characteristic

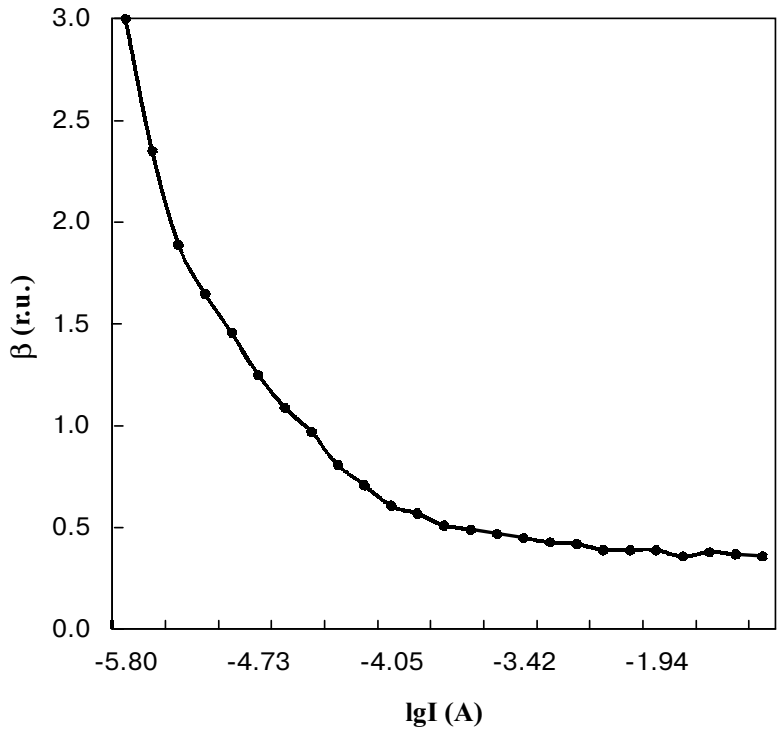

Fig. 5. Derivation from brightness-current characteristic of ionimplanted $p-n$ junction.

the narrow lines in the spectra and the brightness of LED had been established; most of the effective LED had narrow lines at low temperatures. It is a very convenient way to select crystals for green highly bright LED. When the temperature increases, the narrow lines disappear from the spectra. The fact that the sharp-line structures of the electro-luminescence spectra coincide with those of the photoluminescence spectra at low temperatures $(77 \mathrm{~K})$ is an additional indication to support the suggestion that the characteristics of the spectra are due to radioactive defects.

The ion-implanted structures have much faster response times than the diffused ones (Table 2). The switching time is close to $10^{-8} \mathrm{~s}$, which provides wide opportunities for the applications of such LED to optical couples and optical-fiber communication lines. The 


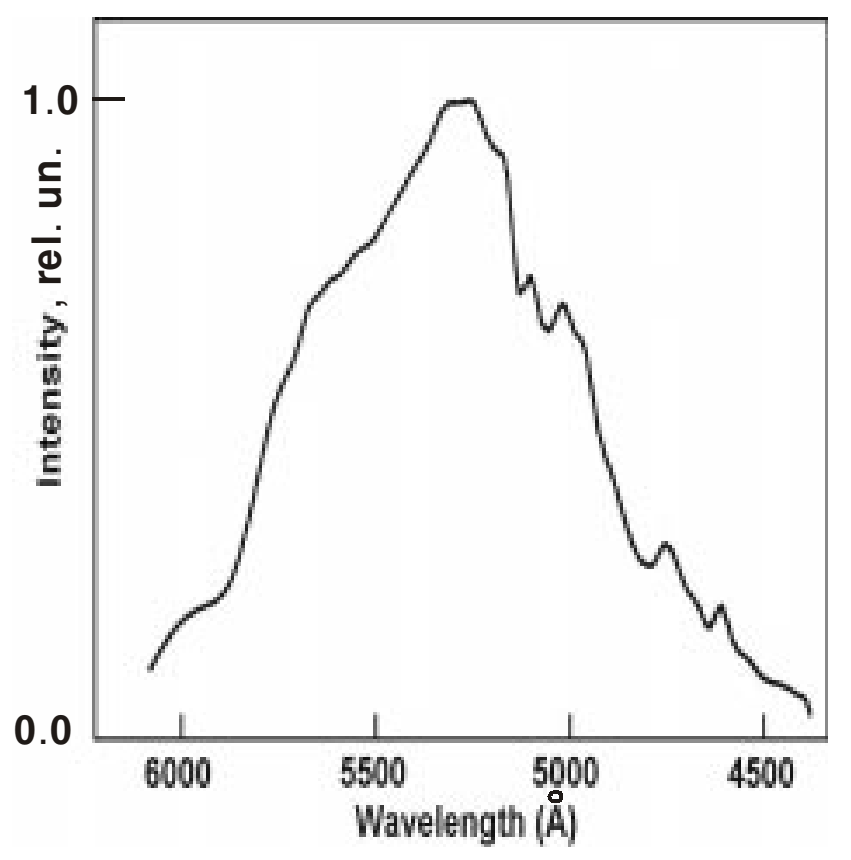

Fig.6. Ion-implanted $p-n$ junction electroluminescence spectrum.

Table 2. LED for the fiber communication line

\begin{tabular}{cccccc}
\hline \hline $\begin{array}{l}\text { Switching Switching Working } \\
\text { voltage } \\
\text { current } \\
(\mathrm{V})\end{array}$ & $\begin{array}{c}\text { Bright- } \\
(\mathrm{mA})\end{array}$ & $\begin{array}{c}\text { Size of } \\
(\mathrm{V})\end{array}$ & $\begin{array}{c}\text { Sess } \\
\left(\mathrm{cd}^{2} \mathrm{~m}^{2}\right)\end{array}$ & $\begin{array}{c}\text { Sight area } \\
\left(\mu \mathrm{m}^{2}\right)\end{array}$ & $\begin{array}{c}\text { Switching } \\
\text { time }\end{array}$ \\
\hline $2.6 \pm 0.2$ & 0.5 & $3.2 \pm 0.1$ & $2000-4000$ & $50 \times 50$ & 0.15 \\
& & & & $80 \times 50$ & 0.01 \\
\hline \hline
\end{tabular}

brightness of the diffused LED is $30-100 \mathrm{~cd} / \mathrm{m}^{2}$ at $10 \mathrm{~mA} / \mathrm{mm}^{2}$, while for the ion-implanted it is 500 $600 \mathrm{~cd} / \mathrm{m}^{2}$ at $10 \mathrm{~mA} / \mathrm{mm}^{2}$ and even $(2-10) \cdot 1000 \mathrm{~cd} / \mathrm{m}^{2}$ for the best samples.

On the other hand, ion-implanted $p-n$ junctions can be applied widely in optical-fiber communication, especially, short communication lines, because of their high speed $\left(10^{-8} \mathrm{~s}\right)$, high stability of light for $10,000 \mathrm{hrs}$, linear brightness-current characteristics up to a current density of $10 \mathrm{~A} / \mathrm{cm}^{2}$, high brightness, absence of brightness degradation, and stability of characteristics over a wide interval of temperatures.

\section{Conclusion}

The characteristics of silicon carbide LEDs were investigated. These included the influence of surface processing, the formation method of the $p$ - $n$ junctions, and the contacts on the properties of the LED. Green SiC LEDs can be used as light sources for optical-fiber communication lines, in the traffic lights, as indicators, in screens and so on. $p$ - $n$ junctions were fabricated by $\mathrm{Al}^{+}$ ion-implantation $6 \mathrm{H}-\mathrm{SiC}$, and annealed at $800-1100^{\circ} \mathrm{C}$. Characteristics for using as effective green LED had been investigated. The brightness of the best ion-implanted $p-n$ junction was found to be about $2000-10000 \mathrm{~cd} / \mathrm{m}^{2}$. The ion-implanted structures showed a high stability of light in the temperature range of $77-600 \mathrm{~K}$.

The pulsing characteristics of these LEDs based on ion-implanted structures had a response time close to $10^{-8} \mathrm{~s}$.

\section{References}

1. S.I.Vlaskina, K.W.Kim, Y.S.Kim, Y.P.Lee, G.S.Svechnikov, Optoelectronics Devices on Silicon Carbide // Journal of the Korean Physical Society, 30(1),pp.117-121(1997).

2. M.A.Capano, R.Santhakumar, J.A.Cooper,Ir., and M.R.Meloch, SiC Ion Implantation Research at Purdue, USA (internet information), 2002. 